\title{
Does entrepreneurship fit her? Women entrepreneurs, gender-role orientation, and entrepreneurial culture
}

\author{
Francisco Liñán (1) • Inmaculada Jaén (1) • \\ Domingo Martín (iD)
}

Accepted: 30 September 2020 / Published online: 28 November 2020

(C) The Author(s) 2020

\begin{abstract}
The present research analyzes the way in which gender-role orientation (GRO) and perceived entrepreneurial culture affect the advancement of women through the different stages in the entrepreneurial process. To do so, a sample of 1195 Spanish women is studied using Bem's Sex Role Inventory to identify their GRO and a perceived regional culture (PRC) scale. The results confirm that women with a masculine or androgynous orientation are more likely to develop entrepreneurial careers. Besides, for masculine GRO women, the perception of a supportive entrepreneurial culture in their region fosters their advancement in entrepreneurship. In contrast, the effect of perceived culture is negative for women with an androgynous GRO. These results contribute to advance knowledge on the entrepreneurial process for women. Based on our results, the debate about women entrepreneurship should be expanded to fully acknowledge the relevance of GRO.
\end{abstract}

\footnotetext{
F. Liñán · I. Jaén · D. Martín

Universidad de Sevilla, Seville, Spain

I. Jaén

e-mail: inmajaen@us.es

D. Martín

e-mail: domartin@us.es

F. Liñán $(\bowtie)$

Anglia Ruskin University, Cambridge, UK

e-mail: flinan@us.es

e-mail: francisco.linan@anglia.ac.uk
}

Keywords Women entrepreneurship · Gender-role orientation · Perceived regional culture - Masculinity . Femininity $\cdot$ Androgyny

JEL classifications $\mathrm{J} 16 \cdot \mathrm{L} 26 \cdot \mathrm{D} 91$

\section{Introduction}

"Context is important for understanding when, how, and why entrepreneurship happens and who becomes involved" (Welter 2011, p. 166). Context is a very wide concept and may encompass several levels and layers (Whetten 2009). In this sense, the institutional context includes economic, political, and cultural aspects (Shane 2003). In particular, culture has received considerable attention as very relevant in influencing entrepreneurship (Krueger et al. 2013). Culture has been found to affect both the formation of entrepreneurial intentions (Shinnar et al. 2012) and the emergence of entrepreneurial behavior (Hayton et al. 2002; Hayton and Cacciotti 2013; Thornton et al. 2011). It may influence the way entrepreneurs behave and the overall level and nature of entrepreneurial activity (Welter and Smallbone 2011). This effect takes place through its influence on actual rules and regulations, on social norms of behavior, and on the shared interpretation of reality (Scott 1995, 2010).

A culture may be more or less supportive of entrepreneurship and the entrepreneurial activity (Kibler et al. 2014). An entrepreneurially supportive culture is one in which the entrepreneurial activity is considered as 
legitimate and desirable. Thus, it will lead to more individuals being involved in the entrepreneurial activity (Mueller and Thomas 2001). However, this positive effect of culture will not be equally strong on all members of society. A considerable amount of literature has focused on the existence of differences in entrepreneurial behavior between men and women (e.g., Gupta et al. 2008, 2009, 2013; Hechavarría et al. 2017; Marlow and McAdam 2013; Marlow and Swail 2014). It is frequently argued that women face cultural obstacles in pursuing an entrepreneurial career (Baughn et al. 2006; Bullough et al. 2017; Jennings and Brush 2013). Consequently, it is not at all surprising that research reports women's level of entrepreneurial activity to be lower than that of men (Hindle et al. 2009; Hughes et al. 2012; Santos et al. 2016).

Nevertheless, research on women's entrepreneurship has argued that a direct comparison with that of men may not be appropriate (Ahl 2006; Marlow and McAdam 2013). Gender stereotypes are an important source of these differences between women's and men's entrepreneurship. Gender stereotypes refer to the consensual beliefs shared by society about typical traits of women and men, and they have an effect on the professional evaluation of people (Broverman et al. 1972). The typical characteristics of women (feminine) are connected with their traditional role as homemakers, while those of men (masculine) are related to their traditional roles as providers (Eagly 1987). Entrepreneurs' activities have also been traditionally associated with masculine traits (de Pillis and Meilich 2006; Gupta et al. 2009; Laguía et al. 2018).

This frequently leads to discrimination against women in entrepreneurship (Bigelow et al. 2014; Brush et al. 2018). Society and culture are seen as discriminating against women and making it more difficult for them to start a venture (Hirschi and Fischer 2013; Marlow and Swail 2014). Therefore, gender stereotypes negatively affect women's intention to pursue an entrepreneurial career path (Gupta et al. 2008, 2009; Shinnar et al. 2012). Gender stereotypes may also explain why women report lower levels of the knowledge and skills required to start a new venture (Allen et al. 2007). In this sense, women often report a lower ability and are less likely to actually become selfemployed (Verheul et al.2012). Gender stereotypes are also relevant at later stages (Gupta et al. 2019), when women entrepreneurs frequently receive less funding (Leitch et al. 2018; Brush et al. 2018) and face difficulties in developing their professional venture networks (Neumeyer et al. 2019).

This approach, however, does not provide sufficient insight into the way women perceive reality and, in particular, the entrepreneurial career path. Nor does it clarify how women react to prevailing cultural norms. The extant literature is far from having fully explained the mechanisms through which an entrepreneurially supportive culture may encourage or discourage women from taking the entrepreneurial path. Research so far has analyzed the influence of culture on entrepreneurship by directly comparing-women vs. men (Shneor et al. 2013; Shinnar et al. 2012, 2018). This would mean that all women are equally affected by this cultural influence. Yet in practice, some women do enter entrepreneurship and become successful entrepreneurs, which is at odds with the general and encompassing negative effect of culture on women's entrepreneurship.

Gender-role orientation (GRO) has been studied to explain different aspects of entrepreneurship, such as self-efficacy (Mueller and Conway Dato-on 2008) or entrepreneurial orientation (Goktan and Gupta 2015). Some researchers have used samples from different countries (Mueller and Conway Dato-on 2013; Goktan and Gupta 2015). However, as far as we are aware, no study has analyzed the joint influence of culture and GRO on entrepreneurship. Given the importance attached to context (and particularly culture) in shaping entrepreneurship behavior in general, and especially that of women, understanding the mechanisms through which this influence takes place is highly relevant.

In this paper, we analyze how perceived culture affects women's involvement in entrepreneurship (understood as self-employment activity). We argue that the influence of the personal perception of culture on entrepreneurial aspirations and behavior is different depending on the individual's GRO. To test this argument, we study a sample of adult women from Spain with different degrees of participation in entrepreneurial activity, ranging from no involvement at all in entrepreneurship to having several years of experience as business owners. The interaction between their perceptions about culture and their GRO is analyzed, and the results confirm their relevance.

This research contributes to the literature on women's entrepreneurship by focusing on the differential effect that perceptions about culture have on the level of entrepreneurial involvement depending on the participants' GRO. The results also contribute to the 
"think entrepreneur, think male" research stream (de Pillis and Meilich 2006; Hancock et al. 2014; Laguía et al. 2018) by explaining how the cultural association between entrepreneurship and men has different encouraging/discouraging effects on women depending on their GRO.

The next section presents the relevant theory and develops our research model and hypotheses. Section 3 describes the methodology used in the empirical analysis, leading to the results in Section 4. These results are discussed in Section 5, and the paper ends with a brief conclusion.

\section{Theory}

\subsection{Gender stereotypes and gender-role orientation}

The social stereotypes describing men and women are different in the large majority of countries (Wood and Eagly 2002). Women are typically described as caring, supportive, kind, or expressive, while men, in turn, are most commonly seen as independent, courageous, aggressive, or autonomous (Gupta et al. 2009). These stereotypical characteristics describe how men and women typically are (descriptive stereotypes) but also how they are expected to be (prescriptive stereotypes) (Shinnar et al. 2018). Both sides of the stereotype are substantially related, since the characteristics describing one sex are directly related to the behavior that is expected from individuals in that sex (Gupta et al. 2009). According to social role theory, the process of individual socialization encourages the acquisition of the traits and patterns of behavior connected with people's gender stereotype (Eagly 1987). This process takes place with the facilitation of parents, schools, social media and the peer group.

Gender-role orientation (GRO) is, therefore, a personal feature affecting one's own attitudes, social behavior, and career choices consistent with socially construed stereotypes (Mueller and Conway Dato-on 2013). In this sense, men's and women's expected way of thinking and behaving is masculine or feminine, respectively (Mueller and Conway Dato-on 2013). However, according to some early but consolidated research (Constantinople 1973), the correspondence between biological sex and the GRO is not bi-univocal. Based on this view, Bem's Sex Role Inventory (BSRI) was developed to measure masculinity and femininity as independent dimensions (Bem 1974). People scoring high in one dimension exhibit the stereotypical traits of that gender (masculine or feminine). In turn, a person scoring high in these two dimensions would jointly exhibit both types of traits (androgynous). Finally, a person scoring low in both would not adhere to the characteristics typical in either of them (undifferentiated). Therefore, women exhibiting the stereotypically feminine orientation (feminine women) represent just one of the four existing possibilities (Spence and Buckner 2000). Other women will have a masculine, an androgynous or an undifferentiated GRO.

With regard to entrepreneurship, research has recently analyzed the relationship between GRO and entrepreneurial activity (Goktan and Gupta 2015; Gupta et al. 2009, 2019; Hancock et al. 2014; Mueller and Conway Dato-On 2008, 2013; Shneor et al. 2013). According to this view, entrepreneurship is connected with the masculine stereotype and characterized by agentic features such as competitiveness and need for achievement or risk-taking (Gupta et al. 2009; Marlow and McAdam 2013; Marlow and Swail 2014). Entrepreneurship has also been linked with ambition and self-confidence, which are related to the masculine stereotype as well (Hancock et al. 2014; Laguía et al. 2018).

These agentic features of entrepreneurship are also close to those of the so-called traditional leadership style (Eagly and Carli 2003). Being assertive and competitive are two of the agentic qualities believed to be required to be a leader (Harrison et al. 2015). According to the "think manager, think male" paradigm, these characteristics are traditionally ascribed to men (Schein 2001). Similarly, entrepreneurs' activities have also been traditionally associated with masculine traits or to the directive leadership style (Laguía et al. 2018). In fact, entrepreneurship has been defended as the essence of leadership (Harrison et al. 2015). Entrepreneurship has also been connected with agentic features, such as risktaking (Caliendo et al. 2015; Verheul et al. 2012) and competitiveness (Bönte and Piegeler 2013). Some authors have proposed a "think entrepreneur, think male" paradigm to recognize this association (de Pillis and Meilich 2006; Laguía et al. 2018). As Harrison et al. (2015: 698) states, “...the language of masculinity, leadership, and entrepreneurship are so intertwined they have become synonymous".

GRO and sex are frequently equated to argue that the masculine stereotype in entrepreneurship produces a negative influence on women's interest in entrepreneurship 
(Camelo-Ordaz et al. 2016). Women are said to perceive greater barriers to carry out entrepreneurial activities, such as in the access to financial resources (Brush et al. 2002) or lacking support or competency (Shinnar et al. 2012). Similarly, their traditional role as family carers may also represent a limitation (Díaz-García and Welter 2013). This would be leading a higher share of women to think that they do not possess the necessary skills and knowledge to be entrepreneurs (Allen et al. 2007; Laguía et al. 2018).

However, this implies an oversimplification of gender stereotypes. Women - the same as men-may exhibit either feminine, masculine, androgynous, or undifferentiated GROs (Bem 1974; Constantinople 1973). In fact, Mueller and Conway Dato-on (2013) find that between 28 and $46 \%$ of women identify themselves with a feminine gender role. Meanwhile, Goktan and Gupta (2015) note $32 \%$ of women with a feminine role orientation. Therefore, the majority of women identifies themselves with alternative gender-role orientations. As a consequence, not all women are equally affected by the association between entrepreneurship and masculine stereotypes.

As Gupta et al. (2009) argue, women who identify themselves with a masculine role orientation are more likely to exhibit entrepreneurial intentions and thus develop entrepreneurial careers. In turn, women with a feminine GRO will fall into the stereotypical category and will be less inclined toward entrepreneurship. Androgynous women exhibit both the traditional male and female characteristics. These women combine assertive and instrumental traits together with compassionate and expressive ones (Pérez-Quintana et al. 2017). Previous research has found androgyny to be associated with higher entrepreneurial self-efficacy (Mueller and Conway Dato-on 2008, 2013). Similarly, this may be connected to more positive leadership skills (Harrison et al. 2015). The balance between feminine and masculine traits makes these individuals more flexible and adaptable to different situations, having a wider repertoire of skills to apply to each situation (Goktan and Gupta 2015).

Previous research in the Spanish context has confirmed the applicability of GRO to the study of entrepreneurship. Hancock et al. (2014) analyzed the mental association in Spain between entrepreneurs and a series of traits that were typically masculine (considered as typical of men), feminine (typical of women), or androgynous (shared by both women and men). They found entrepreneurs to be described by masculine or androgynous traits only. Previous research in Spain has also found the masculine and androgynous GRO to be positively linked with entrepreneurial self-efficacy (Mueller and Conway Dato-On 2013) and with entrepreneurial intentions (Pérez-Quintana et al. 2017). For these reasons we hypothesize as follows:

H1a. Women identifying with the masculine GRO will be more likely involved in entrepreneurship.

H1b. Women identifying with the feminine GRO will be less likely involved in entrepreneurship.

H1c. Women identifying with the androgynous GRO will be more likely involved in entrepreneurship

\subsection{Culture and entrepreneurial behavior}

Culture can be defined as a set of shared beliefs, values, and expectations (Hayton et al. 2002). Hofstede (2003, p. 9) defines culture as "the collective programming of the mind that distinguishes members of one group or category of people from another". It has been wellestablished that the cultural context influences the formation of entrepreneurial intentions (Shinnar et al. 2012; Siu and Lo 2013) and actual entrepreneurial behavior (Hayton et al. 2002; Stenholm et al. 2013; Thornton et al. 2011).

Nevertheless, the focus of our analysis is on individual-level perceptions of culture, rather than aggregated country-level indicators. As entrepreneurship is an individual-level endeavor (Stephan and Uhlaner 2010), it is the personal perceptions about culture that are relevant for the individual to take entrepreneurial action (Autio et al. 2013; Liñán et al. 2016). Using individual-level perceptions of culture has been advocated (McCoy et al. 2005; Shinnar et al. 2012) because considerable heterogeneity exists in how culture is perceived among individuals within a single country (García-Cabrera and García-Soto 2008; Jaén and Liñán 2013; Leung and Morris 2015). Country-level cultural indicators will hardly be able to predict whether and to what extent cultural aspects induce some individuals (but not others) to create a new venture.

A culture is supportive of entrepreneurship if it stresses the values and behaviors connected with entrepreneurship (Mueller and Thomas 2001), thus legitimizing entrepreneurship through the development of institutions facilitating entrepreneurial activity (Thornton 
et al. 2011). The theoretical roots of social legitimacy lie in institutional theory (Scott 1995, 2010). This framework is suitable to assess the influence of cultural contexts on entrepreneurial activity (Kibler et al. 2014; Welter 2011). Institutions are social structures consisting of three institutional pillars, namely "cultural-cognitive, normative, and regulative elements that, together with associated activities and resources, provide stability and meaning to social life" (Scott 1995, p. 33). The cultural-cognitive pillar guides behavior through "deeply entrenched assumptions and conceptions of the "way the world is"" (Scott 2010, p. 7). The normative pillar exerts an influence on behavior through social norms of acceptability and morality, and the regulatory pillar acts through formal rules and related sanctions (Scott 2010). Therefore, the predominant culture shapes individual behavior by affecting individuals' beliefs, their perception about the social rewards and sanctions expected after some action, or the rules that actually enable or constrain people's behavior (Scott 1995).

Culture fosters the development of certain personality traits and motivates individuals to carry out particular behaviors that may not be obvious or desirable in other societies (Mueller and Conway Dato-on 2013). Legitimacy is thus understood as "a generalized perception or assumption that the actions of an entity are desirable, proper or appropriate" (Suchman 1995, p. 574). Individuals tend to behave in a way that is deemed to be socially appropriate and legitimate (Bourdieu 1991; Markus and Kitayama 1991). What constitutes socially legitimate behavior is, in turn, defined through social interactions with other individuals. Providing legitimacy to a certain type of behavior is crucially affected by culture-related aspects and the corresponding social sanctions in general (Kibler et al. 2014; Kibler and Kautonen 2016).

Given that culture reinforces some characteristics while penalizing others, it is likely that some cultures may be more oriented toward entrepreneurship than is the case for others (Shneor et al. 2013). Applying these arguments to the entrepreneurship context implies that the cultural context affects whether firm creation actually occurs or not (Dodd and Anderson 2007; Steyaert 2007). Thus, a supportive culture will legitimize entrepreneurship as a valued activity and one that is approved of by the society (Etzioni 1987).

Given intra-national variations in institutions (including culture), this legitimation process is probably more important at the regional level (Bosma and Schutjens 2011; Kibler et al. 2014). Thus, the prevalence of sociocultural values affects regional levels of firm formation (Davidsson and Wiklund 1997). In particular, in the case of Spain, some previous research has found a relatively high variation between the predominant culture in each region (Jaén and Liñán 2013). For this reason, it seems even more appropriate in this context to focus on the perceptions of respondents about the predominant culture in their region of residence, rather than the Spanish national culture. Therefore, we hypothesize as follows:

H2. Women considering their perceived regional culture to be more favorable to entrepreneurial activity will be more likely involved in entrepreneurship.

\subsection{Gender-role orientation and perceived culture}

Not all cultures are equally supportive of entrepreneurship (Liñán and Fernandez-Serrano 2014). Certain cultures stressing a more masculine dimension (Hofstede 1998) are supposed to be more supportive of entrepreneurial activity (Shneor et al. 2013). In this sense, where the difference between the masculine and the feminine stereotypes is stronger, the social roles of men and women tend to be more differentiated. That is, the cultural context affects the trade-off between a professional career and family interests (Hofstede 1998). It can then be argued that a culture is more supportive of entrepreneurship where the alignment between the "masculine" values linked with entrepreneurship and the national-culture value priorities is stronger (Mueller and Conway Dato-on 2013). Regarding entrepreneur-friendly values, an entrepreneurial culture would be connected with the cultural dimension of masculinity in Hofstede's (2003) framework, or that of mastery in Schwartz's (1999) framework.

This will be related to the admissible career choices available to each person. That is, since entrepreneurship is associated with masculine characteristics (Ahl 2006; Gupta et al. 2009), cultures that are more supportive of entrepreneurship probably differentiate more strongly between the gender stereotypes linked with each professional career option (Laguía et al. 2018). In this sense, Shneor et al. (2013) found that in Norway (scoring low in both Hofstede's masculinity dimension and Schwartz's mastery dimension), the prototypical stereotype of an entrepreneur is less clearly connected with 
masculine traits than is the case for Turkey (scoring high in masculinity and mastery dimensions).

In these more entrepreneurially supportive cultures, gender-role differentiation should be expected to be stronger (Mueller and Conway Dato-on 2013; Shneor et al. 2013). In the case of Spain, regional cultures differ notably. Some regional cultures are clearly considered as supportive of entrepreneurship, while the opposite is considered by others. For instance, Liñán et al. (2011) found the social valuation of entrepreneurship as a career option to be higher in Catalonia than was the case for Andalusia. Similarly, the GEM project defines the regional culture as the social and cultural norms supporting entrepreneurial activity (Reynolds et al. 2005; Reynolds et al. 2008). In the case of Spain, annual reports consistently find more entrepreneurially supportive social and cultural norms in Catalonia, Madrid, or the Basque Country, whereas they are perceived as less favorable in southern regions, such as Andalusia, Extremadura, or Murcia (Peña et al. 2019). Nevertheless, the entrepreneurial masculine stereotype seems to be present throughout the country (Laguía et al. 2018; PérezQuintana et al. 2017).

Women will face tension between, on the one hand, the culturally assigned characteristics of entrepreneurial career paths and, on the other hand, the deviation these paths represent from the perceptions of proper feminine behavior, as dictated by cultural values and norms (Shneor et al. 2013). This tension, however, will depend on the extent to which people identify themselves with the masculine or feminine role orientations. Women identified with the feminine GRO will see themselves as being gentle, tender, affectionate, warm, or sensitive (Bem 1974). If they perceive that their culture is supportive of entrepreneurship (and thus emphasizes masculine-like traits and behaviors that are seen as alien to themselves), they will be less likely to get involved in entrepreneurship. That is, they perceive entrepreneurship as supported by society, but not suited for them. The opposite will happen for women identified with a masculine GRO. They will see themselves as assertive, determined, dominant, or a leader (Bem 1974). Given this self-image, the stronger they perceive culture to be supportive of entrepreneurship (stressing masculine-like traits and behaviors), the more likely it is that they will get involved in entrepreneurship.

Androgynous women identify themselves with both feminine and masculine characteristics. In this case, they feel that they possess masculine-like traits and will therefore feel encouraged by a supportive culture to advance in entrepreneurship (Laguía et al. 2018). Besides, their wider repertoire of skills and learned behaviors (including feminine-like ones) will make them more confident to be able to adapt to the demands and changing requirements of entrepreneurship, given their higher flexibility (Mueller and Conway Dato-on 2013). Additionally, to the extent that entrepreneurship and leadership are closely related concepts (Harrison et al. 2015), the recent change in society toward a more balancedskill concept of leadership (Eagly and Carli 2003; Koenig et al. 2011) would also facilitate the entrepreneurial career of androgynous women.

H3a. For women identifying with the masculine GRO, the relationship between the perceived supportiveness of regional culture and their involvement in entrepreneurship will be stronger.

$\mathrm{H} 3 \mathrm{~b}$. For women identifying with the feminine GRO, the relationship between the perceived supportiveness of regional culture and their involvement in entrepreneurship will be weaker.

$\mathrm{H} 3 \mathrm{c}$. For women identifying with the androgynous GRO, the relationship between the perceived supportiveness of regional culture and their involvement in entrepreneurship will be stronger.

\subsection{Research model and context characteristics}

Figure 1 summarizes our research model and illustrates the hypotheses to be tested in the empirical analysis. But, of course, several other elements may affect the entrepreneurial decision of women in Spain. In this sense, we have argued that it is the individually perceived culture which is important to make individual decisions. However, several previous research works have used aggregate measures of culture or country proxies to control for culture (Goktan and Gupta 2015; Liñán and Fernandez-Serrano 2014; Mueller and Conway Dato-on 2013). In this case, the regional level measures of culture from the GEM Report Spain 2018 (Peña et al. 2019) are available. The global valuation of the entrepreneurial culture in Spain is 3.0 (in a scale from 1 to 5), which is higher than the 2.7 average for European innovation-driven countries (Peña et al. 2019). The entrepreneurial culture in the Spanish regions ranges from a minimum of 2.3 (Asturias) to a maximum of 3.4 (Catalonia). 
The other most relevant set of variables known to affect entrepreneurship involvement is human capital. This includes both education and experience. Regarding the former, the specialized knowledge provided in higher education should facilitate entry into entrepreneurship, as indicated by the higher entrepreneurial activity of Spanish university graduates (Peña et al. 2019). In this sense, Noguera et al. (2015) argue that, in Spain, this is especially important for women, since it may serve to compensate for possible discrimination or other barriers. Similarly, specific entrepreneurship education is found to be positively related to entrepreneurial outcomes (Martin et al. 2013; Nabi et al. 2017; Nabi et al. 2018). In Spain, a considerable boost has been provided to entrepreneurship education in recent years, both from the public and the private sectors (Hernández-Sánchez et al. 2019). Recent data indicate that over $52 \%$ of entrepreneurs in Spain have received entrepreneurship education (Peña et al. 2019).

On the other hand, previous labor experience (both as an entrepreneur and as an employee) is also considered as a positive influence on entrepreneurship (Bönte and Piegeler 2013; Kautonen et al. 2015). In the case of Spain, previous research has found that work experience is positively related to entrepreneurial intentions (Liñán et al. 2011, 2016). Finally, age is commonly included as a control variable, since research has regularly found it to be related to entrepreneurial activity (Kibler and Kautonen 2016; Verheul et al. 2012), as it facilitates the accumulation of both financial and human capital. In Spain, age is found to be only indirectly related to entrepreneurial intention (Liñán et al. 2011, 2016), but entrepreneurial activity is highest in the 25- to 44-yearold age group (Peña et al. 2019).

\section{Methodology}

\subsection{Sample}

The population under study is made up of adult women in Spain presenting different levels of involvement in entrepreneurship (as defined in Section 3.2.1 below). The rates of involvement in entrepreneurship for men are relatively low in this country and even lower for women (Peña et al. 2019). Therefore, a purposeful sample was used. Data were collected between March and May 2018. On the one hand, a number of entrepreneurship support organizations were approached, and, through them, potential, nascent, and actual entrepreneurs were invited to participate. The organizations included four regional ones (Andalucia Emprende, Catalunya Empren, Bic Galicia, and Emprendelo [in Madrid]) and two national networks of centers (Chambers of Commerce and the Explorer program). Exact response rates cannot be produced because most centers have not informed of the number of invitations that they sent out. ${ }^{1}$ In the case of Explorer, they sent invitations to over 1000 participants in their annual incubation program, and obtained 137 valid responses (a response rate of around 13\%), 54 of them were women. These response rates are in line with the $9.4 \%$ reported by Deutskens et al. (2004) for a similarly structured online questionnaire. More recently, in a business context, Frese et al. (2019) obtained a $16.8 \%$ response rate with a shorter questionnaire. Overall, we collected 620 responses through entrepreneurship centers (271 of them were women).

On the other hand, adults with a university education (alumni from a large university in the Andalusian region who have graduated in the last 5 years) were also approached and invited to participate. In this case, a total of 22,400 alumni were invited, and 1721 complete responses were returned (924 of them were women), representing a $7.7 \%$ response rate. This is in line with the $8.6 \%$ response rate reported by Breznitz and Zhang (2019) for a similar population of university alumni.

The final sample used in this study is made up of 1195 women, who represent $51 \%$ of 2341 complete responses received. The distribution of both subsamples is presented in Table 1. Women in the sample were on average 29.3 years old, ranging from a minimum of 16 to a maximum of 65 . Regarding education, $56.9 \%$ had a postgraduate degree (master or doctorate), while the remaining had a university degree $(37.4 \%)$ or lower educational qualifications (5.7\%). Additionally, 28.2\% of the respondents had received specific entrepreneurship education to start a venture. The respondents tended to have employee experience ( $86.6 \%$ ), with up to $38.3 \%$ of the sample having had more than 3 years of experience. In turn, only $24.9 \%$ of them had self-employment experience, and only $7.4 \%$ of the sample had more than 3 years of this experience.

\footnotetext{
${ }^{1}$ Due to data protection regulations, the researchers did not have access to the personal information of the respondents. In turn, the centers forwarded our invitation message to their affiliates/users.
} 
Fig. 1 Research model and hypotheses

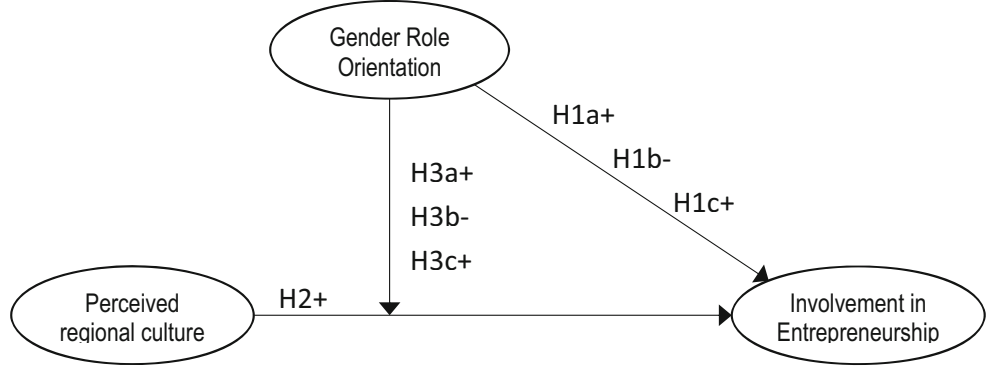

The majority of the respondents lives in Andalusia (937 women, $78.5 \%$ ), followed by Catalonia (73 women, $6.1 \%$ ), Madrid (57 cases, 4.8\%), and Galicia (47 cases, $3.9 \%)$. The remaining regions together represent $6.8 \%$ of the sample (81 women). Respondents from Andalusia are especially frequent in the universityalumni subsample (86\%), more so than is the case for the entrepreneurship-center subsample (50\%). This difference will be controlled for in the statistical analysis (see below). As mentioned above, regional cultural differences are noteworthy between the Spanish regions. Andalusia presents a less favorable entrepreneurial culture (Peña et al. 2019) as well as a lower income level. Galicia is close to the Spanish average both regarding entrepreneurial culture and income. In contrast, Madrid and Catalonia are clearly above the average in both aspects.

\subsection{Measures}

\subsubsection{Dependent variable}

The dependent variable "entrepreneurial involvement" measures the stage respondents are at in the entrepreneurial process. They answered the question: "What stage are you at in the creation process of your venture?" The available responses are: "I have not thought about it yet" (coded as 1 and meaning the individual is not involved in entrepreneurship), "I expect to create it in the next 3 years" (coded 2 and corresponding to the potential entrepreneur), "I am currently creating it" ( 3 , meaning the person is a nascent entrepreneur), "I created it in the last 3 years" (4, for new entrepreneurs), and "I created it more than three years ago" (coded as 5 and representing consolidated entrepreneurs). Table 1 presents the distribution of responses for this variable. This classification into stages (not involved, potential, nascent, new, and consolidated entrepreneurs) is frequently used in academic research (Álvarez et al. 2014; Caliendo et al. 2009; Reynolds et al. 2005).

As may be seen, around half of the participants are not involved in entrepreneurship to any extent. Given that the great majority of the Spanish population is equally not involved $(80.7 \%$, according to the last GEM report) (Peña et al. 2019), the sample distribution is skewed toward this end to guarantee representativeness. On the other hand, as may be expected, the proportion of not-involved individuals is higher for the alumni subsample, whereas it is very low (only 4.8\%) for the entrepreneurship-center subsample). These latter individuals are probably registered in the entrepreneurship center as participating in some training or similar activity and have received the invitation to participate in this study for this reason.

\subsubsection{Independent variables}

Gender-role orientation (GRO) We employed a 12item simplified version of Bem's Sex Role Inventory (BSRI) scale to measure GRO (Bem 1974). The validity of this simplified version was confirmed for a Spanish sample (Mateo and Fernández 1991). The BSRI assumes a 2-factor structure representing the femininity and masculinity dimensions (Ahmed et al. 2016; Bem 1981). This structure has been satisfactorily confirmed by a number of recent studies (Ahmed et al. 2016; Carver et al. 2013). As done in similar previous research (Ahmed et al. 2016; Carver et al. 2013; Mateo and Fernández 1991), responses to the 12 items comprising the scale were factor-analyzed to compute the masculinity and femininity factors. The results from the exploratory factor analysis (EFA) were fully satisfactory and yielded two factors (masculinity and femininity), explaining $55.7 \%$ of the overall variance. They are included in the Appendix A1.

According to Bem's androgyny model (Bem 1974), the respondents were separated based on their gender 
Table 1 Sample distribution

\begin{tabular}{|c|c|c|c|c|c|c|}
\hline Women sample & $\begin{array}{l}1 \\
\text { Have not } \\
\text { thought about it }\end{array}$ & $\begin{array}{l}2 \\
\text { Plan to do it in } \\
\text { the next } 3 \text { years }\end{array}$ & $\begin{array}{l}3 \\
\text { Presently starting } \\
\text { a venture }\end{array}$ & $\begin{array}{l}4 \\
\text { Venture started in } \\
\text { the last } 3 \text { years }\end{array}$ & $\begin{array}{l}5 \\
\text { Started more than } \\
3 \text { years ago }\end{array}$ & Total \\
\hline $\begin{array}{l}\text { Entrepreneurship centers } \\
\text { - Andalusia } \\
\text { - Rest of Spain }\end{array}$ & $\begin{array}{l}13 \\
(4.8 \%) \\
39 \% \\
61 \%\end{array}$ & $\begin{array}{l}53 \\
(19.6 \%) \\
37 \% \\
63 \%\end{array}$ & $\begin{array}{l}64 \\
(23.6 \%) \\
31 \% \\
69 \%\end{array}$ & $\begin{array}{l}103 \\
(38.0 \%) \\
57 \% \\
43 \%\end{array}$ & $\begin{array}{l}38 \\
(14.0 \%) \\
84 \% \\
16 \%\end{array}$ & $\begin{array}{l}271 \\
(100.0 \%) \\
50 \% \\
50 \%\end{array}$ \\
\hline $\begin{array}{l}\text { University alumni } \\
\text { - Andalusia } \\
\text { - Rest of Spain }\end{array}$ & $\begin{array}{l}576 \\
(62.3 \%) \\
88 \% \\
12 \%\end{array}$ & $\begin{array}{l}227 \\
(24.6 \%) \\
82 \% \\
18 \%\end{array}$ & $\begin{array}{l}62 \\
(6.7 \%) \\
87 \% \\
13 \%\end{array}$ & $\begin{array}{l}47 \\
(5.1 \%) \\
85 \% \\
15 \%\end{array}$ & $\begin{array}{l}12 \\
(1.3 \%) \\
92 \% \\
8 \%\end{array}$ & $\begin{array}{l}924 \\
(100.0 \%) \\
86 \% \\
14 \%\end{array}$ \\
\hline $\begin{array}{l}\text { Total } \\
\text { - Andalusia } \\
\text { - Rest of Spain }\end{array}$ & $\begin{array}{l}589 \\
(49.3 \%) \\
87 \% \\
13 \%\end{array}$ & $\begin{array}{l}280 \\
(23.4 \%) \\
75 \% \\
25 \%\end{array}$ & $\begin{array}{l}126 \\
(10.5 \%) \\
59 \% \\
41 \%\end{array}$ & $\begin{array}{l}150 \\
(12.6 \%) \\
67 \% \\
33 \%\end{array}$ & $\begin{array}{l}50 \\
(4.2 \%) \\
86 \% \\
14 \%\end{array}$ & $\begin{array}{l}1195 \\
(100.0 \%) \\
78 \% \\
22 \%\end{array}$ \\
\hline
\end{tabular}

groups (Shifren and Bauserman 1996; Goktan and Gupta 2015). To do so, the median split method was used to classify the study population into four genderrole groups (Lenney 1991). This method is consistent with Mueller and Conway Dato-on (2013) and Goktan and Gupta (2015). The median masculinity and femininity scores for all respondents were .071 and .096, respectively. The women in our sample with both a masculinity score and a femininity score above their medians were categorized as androgynous (28.4\%). The respondents with a masculinity score below 0.071 and a femininity score above 0.096 were categorized as feminine $(24.6 \%)$. The respondents with a masculinity score above 0.071 and a femininity score below 0.096 were categorized as masculine $(21.2 \%)$. The respondents with both a masculinity and a femininity score below their medians were categorized as undifferentiated $(25.8 \%)$.

Perceived regional culture (PRC) This variable was measured through a 5-item scale identifying cultural values that are positively related to entrepreneurship. The scale follows the National Expert Survey from the Global Entrepreneurship Monitor (Reynolds et al. 2005; Reynolds et al. 2008), which was originally developed based on McGrath and MacMillan (1992). The only difference is that the PRC refers to the "predominant culture in my region", rather than "in my country". The respondents were asked to rate the extent to which they perceived that the predominant culture in their region stresses each of the five values typically associated with entrepreneurship. The list of items is included in the
Appendix A2. An EFA confirmed that they load in one single factor (see Appendix A2), explaining $69.46 \%$ of the overall variance.

\subsubsection{Control variables}

According to the literature reviewed in Section 2.4 above, a number of variables were included as controls, since they are frequently found to affect entrepreneurial decisions. Age was measured in years. We have also controlled for the number of dependents (children, elderly or disabled) living with the respondents, as a potentially relevant personal circumstance. Three variables were used to control for experience and education. Firstly, the variable Master takes the value 1 for those women who presently have or are currently studying a Master or doctorate degree and 0 if this is not the case. Work experience is assessed through two variables. Employee experience indicates whether the respondent has previous work experience as an employee, while self-employment experience refers to experience as a self-employed person/entrepreneur. They are both devised as ordinal variables to consider the length of experience. They take the value 0 if the respondent has no experience, 1 if they have less than 1 year of experience, 2 for up to 3 years of experience, and value 3 when they have more than 3 years of experience. Entrepreneurship_training is a binary variable taking the value 1 for those women who have received specific training in entrepreneurship and 0 in the negative case.

Role models (RM) are frequently cited as a reference and a source of vicarious learning (Bandura 1986). 
Some authors argue that the effect is different depending on the valuation made by the individual about the model's performance as an entrepreneur (Scherer et al. 1991). Therefore, we have controlled for the personal knowledge and valuation of the entrepreneurial activity of a number of relatives and acquaintances who can serve as a reference for the respondent: father, mother, relatives, friends, and workmates role models. Each of these role models is controlled for by using two dummy variables. The first one refers to positive $R M$ and takes the value 1 if the respondent has a favorable evaluation of this role model's entrepreneurial activity, while it takes the value 0 if the respondent does not personally know any such entrepreneurs. The negative $R M$ variable takes the value 1 if the respondent has an unfavorable valuation of this person's entrepreneurial activity and 0 if she does not know any such model.

Finally, the two subsamples making up our dataset have different characteristics. As shown in Table 1, the participants coming from entrepreneurship centers tend to advance more in the entrepreneurial process. For this reason, we have decided to control for this circumstance. Thus, E-center is a dichotomous variable taking the value 1 if the respondent was contacted through an entrepreneurship center and 0 if the respondent is an alumna from our selected university. Additionally, we also included an aggregate measure of the regional culture, as estimated by the GEM project (Peña et al. 2019), to control for the effect of aggregate culture. ${ }^{2}$ Descriptive statistics for all the variables are reported in Table 2. These two variables together should also serve to control for the different relative presence of respondents from Andalusia in both subsamples.

\subsection{Data analysis}

Since the dependent variable $y$ is ordinal, we use an ordered logit model (OLM) to test the research hypotheses. We use the following specification:

$\operatorname{Pr}\left(y_{i}=m \mid \boldsymbol{x}\right)=F\left(\tau_{m}-\boldsymbol{x}_{i}^{\prime} \boldsymbol{\beta}\right)-F\left(\tau_{m-1}-\boldsymbol{x}_{i}^{\prime} \boldsymbol{\beta}\right)$ for $m=1$ to 5, where $F(z)=\left(1+e^{z}\right)^{-1}$ and $\tau_{1}, \ldots, \tau_{4}$ are named cutpoints or thresholds with $\tau_{0}$ being defined as $-\infty$ and $\tau_{5}$ as $\infty . x_{i}$ is the vector of independent variables for the $\mathrm{i}$-th individual and $\beta$ is the vector of coefficients.

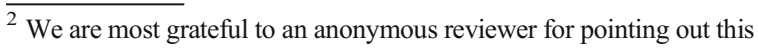
issue to us.
}

OLM is also known as the proportional odds model because if we consider the odds $\Omega(m)_{>m \mid \leq m}=\operatorname{Pr}(y>m \mid$ $\left.\boldsymbol{x}_{\boldsymbol{i}}\right) / \operatorname{Pr}\left(y \leq m \mid \boldsymbol{x}_{\boldsymbol{i}}\right)=\exp \left(\boldsymbol{x}^{\prime} \boldsymbol{\beta}-\tau_{m}\right)$, then $\operatorname{odds}\left(\mathrm{m}_{1}\right)$ and $\operatorname{odds}\left(\mathrm{m}_{2}\right)$ have the same ratio for all independent variable combinations. The ordinal logistic regression model involves the assumption that the $\beta$ coefficients are the same for all the categories, such that the estimation results are a set of parallel lines, one for each category of the dependent variable. The test of parallel lines showed no significant result for the study variables in our model, which indicates that the ordered regression model is suitable for this case. The model was estimated using the maximum likelihood method employing the STATA software package.

\section{Results}

Table 3 presents the results of the estimated models using the undifferentiated gender-role orientation (GRO) category as the base and reference. The interpretation of coefficients is given in terms of ordered logodds (logits). Model 1 includes the other three (masculine, feminine, and androgynous) GROs and the perceived regional culture (PRC) as explanatory variables. The possible existence of multicollinearity was tested and no evidence of this problem was found. The control variables generally have the expected signs. In particular, the coefficient for the E-center variable is positive and significant, with a very high effect size $(\beta=2.44$, $p<.001)$. This is reflecting that entrepreneurship-center respondents advance more in the entrepreneurial process than is the case for university alumni.

Additionally, the aggregate measure of regional culture (GEM) is negative and significant $(\beta=-.650$, $p<.005$ ). Thus, women in regions where culture is more supportive of entrepreneurship tend to advance less in the entrepreneurial process. This is reflecting the fact that Andalusia, despite exhibiting a less favorable regional culture, presents a relatively high rate of entrepreneurship, with a larger share of necessity entrepreneurship than is the case for Spain (see Peña et al. 2019). In this sense, this regional-level variable ("Regional Culture GEM") also serves to control for the relatively large share of respondents from Andalusia.

Age has a positive and significant effect in entrepreneurship involvement $(\beta=.049, p<.001)$. In contrast, cohabiting with dependent people is not significant $(\beta=.119$, n.s.). Neither having a postgraduate degree 
Table 2 Descriptive statistics

\begin{tabular}{|c|c|c|c|c|}
\hline Variable & Mean & Std. Dev. & Min & Max \\
\hline Perceived regional culture (PRC) & .045 & .981 & -1.98 & 2.37 \\
\hline Undifferentiated GRO & .258 & .438 & 0 & 1 \\
\hline Masculine GRO & .212 & .409 & 0 & 1 \\
\hline Feminine GRO & .246 & .431 & 0 & 1 \\
\hline Androgynous GRO & .284 & .451 & 0 & 1 \\
\hline E-center & .214 & .411 & 0 & 1 \\
\hline Regional culture (GEM) & 2.505 & .262 & 2.3 & 3.4 \\
\hline Age & 29.265 & 7.206 & 16 & 65 \\
\hline Dependents & .358 & .767 & 0 & 4 \\
\hline Master & .569 & .495 & 0 & 1 \\
\hline Entrepreneurship training & .282 & .45 & 0 & 1 \\
\hline Employee experience & 1.884 & 1.066 & 0 & 3 \\
\hline Self-employment experience & .482 & .929 & 0 & 3 \\
\hline Father RM positive & .246 & .431 & 0 & 1 \\
\hline Mother RM positive & .132 & .339 & 0 & 1 \\
\hline Other relative RM positive & .424 & .494 & 0 & 1 \\
\hline Friend RM positive & .469 & .499 & 0 & 1 \\
\hline Workmate RM positive & .434 & .496 & 0 & 1 \\
\hline Father RM negative & .062 & .241 & 0 & 1 \\
\hline Mother RM negative & .033 & .178 & 0 & 1 \\
\hline Other relative RM negative & .095 & .294 & 0 & 1 \\
\hline Friend RM negative & .095 & .294 & 0 & 1 \\
\hline Workmate RM negative & .111 & .314 & 0 & 1 \\
\hline
\end{tabular}

$N=1194$, since one respondent did not provide her age

$(\beta=-.128$, n.s.) nor entrepreneurship education $(\beta=.140$, n.s. $)$ is significant in explaining entrepreneurship involvement. The coefficients, though, are as expected. Employee experience is not significant $(\beta=.038$, n.s. $)$, while self-employment experience is $(\beta=.521, p<.001)$. Personally knowing a role model $(\mathrm{RM})$ is only significant when the RM is a workmate $(\beta=.755, p<.001$, for the positive $\mathrm{RM}$, and $\beta=.449$, $p<.033$ for the negative RM). Workmates, then, represent a source of inspiration for women, regardless of whether their experience is seen as positive or negative.

Regarding the hypotheses, Model 1 in Table 3 provides support for hypothesis H1a, since the masculine GRO is positively and significantly $(\beta=.390, p<.024)$ related to advancement in the entrepreneurial process (compared to the undifferentiated GRO). In turn, H1b is not supported, because the feminine GRO is not related to entrepreneurial involvement $(\beta=.070$, n.s.). The coefficient for androgynous GRO is positive and significant $(\beta=.390, p<.016)$, granting support to $\mathrm{H} 1 \mathrm{c}$. On the other hand, $\mathrm{H} 2$ is not supported, since the coefficient for perceived regional culture (PRC) is not significant $(\beta=-.082$, n.s.).

Model 2 includes the interaction terms to test hypotheses H3. The coefficient for control variables, the GROs, and their significance levels are similar to those in Model 1. The coefficient for PRC represents the influence of culture for undifferentiated GRO women, which is the base category. Meanwhile, the coefficients for the interaction terms reflect the differential effect of PRC for masculine, feminine, or androgynous GRO women compared to the reference group (undifferentiated GRO women). H3a refers to the interaction between the masculine GRO and PRC. As may be seen, this is supported, since the differential effect of PRC is positive and significant $(\beta=.355, p<.042)$ for women with a masculine GRO (compared to undifferentiated GRO women). In turn, H3b is not supported, since the 
Table 3 Results of the ordered logit model

\begin{tabular}{|c|c|c|c|c|c|c|}
\hline \multirow[t]{2}{*}{ Explanatory variables } & \multicolumn{3}{|l|}{ Model 1} & \multicolumn{3}{|l|}{ Model 2} \\
\hline & $\beta$ & SE & $p$ value & $\beta$ & SE & $p$ value \\
\hline Masculine GRO & $0.3896 * *$ & $(0.1725)$ & 0.0239 & $0.3720 * *$ & $(0.1732)$ & 0.0317 \\
\hline Feminine GRO & 0.0699 & $(0.1700)$ & 0.6810 & 0.0715 & $(0.1701)$ & 0.6744 \\
\hline Androgynous GRO & $0.3896 * *$ & $(0.1616)$ & 0.0159 & $0.4037 * *$ & $(0.1618)$ & 0.0126 \\
\hline Perceived regional culture (PRC) & -0.0824 & $(0.0603)$ & 0.1697 & -0.1573 & $(0.1240)$ & 0.2046 \\
\hline Masculine GRO * PRC & & & & $0.3552 * *$ & $(0.1744)$ & 0.0417 \\
\hline Feminine GRO * PRC & & & & 0.1003 & $(0.1825)$ & 0.5826 \\
\hline Androgynous GRO * PRC & & & & -0.0761 & $(0.1601)$ & 0.6345 \\
\hline E-center & $2.4114 * * *$ & $(0.1867)$ & 0 & $2.4376^{* * *}$ & $(0.1870)$ & 0 \\
\hline Regional culture (GEM) & $-0.6360 * * *$ & $(0.2330)$ & 0.0063 & $-0.6504 * * *$ & $(0.2337)$ & 0.0054 \\
\hline Age & $0.0496 * * *$ & $(0.0109)$ & 0 & $0.0487 * * *$ & $(0.0109)$ & 0 \\
\hline Dependents & 0.1236 & $(0.0775)$ & 0.1135 & 0.1189 & $(0.0779)$ & 0.1268 \\
\hline Master & -0.1229 & $(0.1238)$ & 0.3206 & -0.1277 & $(0.1241)$ & 0.3034 \\
\hline Entrepreneurship training & 0.1533 & $(0.1345)$ & 0.2542 & 0.1404 & $(0.1348)$ & 0.2978 \\
\hline Employee experience & 0.0404 & $(0.0646)$ & 0.5317 & 0.0379 & $(0.0648)$ & 0.5589 \\
\hline Self-employment experience & $0.5106^{* * *}$ & $(0.0750)$ & 0 & $0.5214 * * *$ & $(0.0751)$ & 0 \\
\hline Father RM positive & 0.2352 & $(0.1502)$ & 0.1175 & 0.2252 & $(0.1502)$ & 0.1340 \\
\hline Mother RM positive & -0.1443 & $(0.1877)$ & 0.4421 & -0.1264 & $(0.1877)$ & 0.5008 \\
\hline Other relative RM positive & 0.1667 & $(0.1282)$ & 0.1936 & 0.1713 & $(0.1285)$ & 0.1826 \\
\hline Friend RM positive & 0.1731 & $(0.1347)$ & 0.1988 & 0.1609 & $(0.1351)$ & 0.2334 \\
\hline Workmate RM positive & $0.7530 * * *$ & $(0.1333)$ & 0 & $0.7546 * * *$ & $(0.1335)$ & 0 \\
\hline Father RM negative & -0.1765 & $(0.2746)$ & 0.5204 & -0.1961 & $(0.2764)$ & 0.4780 \\
\hline Mother RM negative & -0.3543 & $(0.3923)$ & 0.3665 & -0.3015 & $(0.3934)$ & 0.4434 \\
\hline Other relative RM negative & -0.1382 & $(0.2276)$ & 0.5438 & -0.1271 & $(0.2291)$ & 0.5789 \\
\hline Friend RM negative & -0.2761 & $(0.2281)$ & 0.2261 & -0.2914 & $(0.2287)$ & 0.2027 \\
\hline Workmate RM negative & $0.4553 * *$ & $(0.2101)$ & 0.0302 & $0.4492 * *$ & $(0.2107)$ & 0.0330 \\
\hline$\tau_{1}$ & $1.1476^{*}$ & $(0.6369)$ & & $1.0763^{*}$ & $(0.6386)$ & \\
\hline$\tau_{2}$ & $2.7716^{* * *}$ & $(0.6431)$ & & $2.7086^{* * *}$ & $(0.6448)$ & \\
\hline$\tau_{3}$ & $3.8561 * * *$ & $(0.6497)$ & & $3.7993 * * *$ & $(0.6513)$ & \\
\hline$\tau_{4}$ & $6.1078 * * *$ & $(0.6735)$ & & $6.0667 * * *$ & $(0.6751)$ & \\
\hline
\end{tabular}

$S E$ standard errors. Significance levels: $* * * p<0.01, * * p<0.05, * p<0.1$

regression coefficient for the feminine GRO * PRC interaction is not significant $(\beta=.100$, n.s.). Finally, $\mathrm{H} 3 \mathrm{c}$ is likewise not supported. The coefficient for the androgynous $\mathrm{GRO} * \mathrm{PRC}$ interaction (Table 3 ) is nonsignificant $(\beta=-.076$, n.s.), indicating no difference with the undifferentiated GRO women in the reference group.

As mentioned above, these results are obtained using the undifferentiated GRO women as the reference category. Similar equations could be estimated using any other category as a reference. In Table 4 , we present the differential effect of PRC for each GRO category (rows) against all others (columns). As can clearly be seen, the effect of PRC for masculine GRO women is more positive than is the case for any other category, and this difference is significant against androgynous and undifferentiated GRO women. In contrast, the effect of PRC for androgynous GRO women is more negative in general and significantly so against masculine GRO women. Overall, then, there seems to be a clear interaction between GRO and PRC, since the effect of PRC is clearly different depending on the GRO of women. Nevertheless, this interaction is not as we expected, since only hypothesis $\mathrm{H} 3 \mathrm{a}$ is partially supported. 
Figure 2 presents the effect of culture for each GRO category. The curves in Fig. 2 should be interpreted as the relative probability of advancing in the entrepreneurial process $(m>1)$ compared to not being involved $(m=$ 1) when the level of PRC varies (see Appendix A3 for details on the computation of these curves). When PRC is zero (around its average value), the odds of advancing into entrepreneurship are clearly higher for masculine and androgynous GRO women (compared with their feminine and undifferentiated GRO counterparts). This is consistent with the results for hypotheses H1 (Table 3, Model 1). As the PRC becomes more favorable, the odds for masculine GRO women to advance into entrepreneurship are higher. In contrast, the odds for androgynous GRO women to advance into entrepreneurship are lower when they perceive the regional culture as more supportive of entrepreneurial activity.

\section{Discussion}

This study offers very interesting insight concerning the relationship between gender-role orientation (GRO) and culture, on the one hand, and the entrepreneurial inclination and behavior of women, on the other hand. It confirms that women with a masculine or androgynous GRO are generally more likely to advance through the entrepreneurial process than is the case for feminine or undifferentiated GRO women. Additionally, despite not finding a general relation between perceived regional culture (PRC) and entrepreneurial involvement, there are differential patterns for some GROs. When the regional culture is perceived as more supportive, masculine GRO women are more likely to advance into entrepreneurship (than is the case for undifferentiated and androgynous GRO women).

The fact that perceived cultural support of entrepreneurship has no clear relationship with entrepreneurial involvement is in conflict with some previous evidence (e.g., Kibler and Kautonen 2016; Liñán et al. 2016). Nevertheless, it is not unprecedented. Kibler et al. (2014) found no direct effect for the perceived regional social legitimacy of entrepreneurship. In turn, they found a moderating effect, where a more positive social legitimacy was linked with stronger relationships between other variables in their model. In our case, the lack of a direct relationship is probably masking the fact that the effect is different for each GRO category of women, as may be observed in Fig. 2.
Contrary to our expectation, no significant effect of an entrepreneurially supportive culture is found for feminine women. More surprisingly, the relation is negative for androgynous women (when compared with masculine women). Three possible interpretations emerge. In the first place, the sample composition may be relevant, since our sample is made up of women only, while previous studies have analyzed a combined sample (and frequently, with a majority of men) (e.g., Goktan and Gupta 2015; Mueller and Conway Dato-on 2013). In this sense, we do find a positive relationship between culture and entrepreneurship for masculine GRO women. Given that the masculine GRO is more frequent in men, this may help explain this apparent contradiction.

Secondly, the measure for PRC is probably connected with a masculine stereotype of entrepreneurship, as hypothesized by the "think entrepreneur, think male" paradigm (de Pillis and Meilich 2006; Gupta et al. 2009; Laguía et al. 2018). The PRC scale items (Reynolds et al. 2008) associate entrepreneurial support with specific characteristics (see Appendix) which are quite close to stereotypically masculine ones, such as autonomy, risk taking, independence, competitiveness, assertiveness, self-reliance, and ambition (Goktan and Gupta 2015; Gupta et al. 2008, 2009; Hancock et al. 2014; Mueller and Conway Dato-on 2013). Only creativity is associated with an androgynous character (Hancock et al. 2014; Mueller and Conway Dato-on 2013). Therefore, PRC could be measuring the extent to which respondents perceive their regional culture supports a traditionally masculine view of entrepreneurship.

This would explain why masculine GRO women tend to advance more in entrepreneurship when they perceive their culture as more supportive. In the case of androgynous women, though, there seems to be a mismatch between their view of entrepreneurship and that supported by the regional culture. In this sense, "the traditional gender-role stereotypes linked with entrepreneurship are more persistent in Spain than in the United States" (Mueller and Conway Dato-on 2013: 16). Given the close relationship between leadership and entrepreneurship (Harrison et al. 2015), it could be argued that a traditional (masculine) entrepreneurship style is more prevalent in Spain than an alternative transformational (androgynous) style (Eagly and Carli 2003). The subtle change that has been observed in other countries toward the transformational style (Koenig et al. 2011) would not be apparent in Spain. Therefore, androgynous women have a greater tendency to get involved in entrepreneurship, and they 
probably try to develop a transformational style. However, when they perceive their culture to be supportive of traditional entrepreneurship, they are discouraged.

Thirdly, since we are using cross-sectional data, we cannot rule out the possibility of reversed causality. ${ }^{3}$ That is, as androgynous women advance through the entrepreneurial process, they find that the culture does not support their way of enacting entrepreneurship. Thus, their perception about PRC becomes more negative. In this sense, a promising stream of literature studies the development of the entrepreneurial identity throughout the entrepreneurial process (Down and Reveley 2004; Lounsbury and Glynn 2001). As androgynous women develop their entrepreneurial career, they probably find an increased mismatch between their personal self and the socially expected entrepreneurial identity.

Our results expand those of relevant previous research in this area. Thus, Mueller and Conway Dato-on (2013) found that androgynous and masculine GRO individuals (jointly including women and men) exhibit higher entrepreneurial self-efficacy than is the case for feminine individuals. Goktan and Gupta (2015), in turn, found androgynous individuals (again in a joint sample) to exhibit the highest individual entrepreneurial orientation, followed by masculine GRO respondents. Their studies explained individual perceptions. Our results go further in replicating their findings (a) for the case of actual entrepreneurship involvement and (b) for a women-only sample. In this way, we follow the advice that research should try "to unpick the complex nature of the female entrepreneurial endeavor so that it can be better understood rather than unduly criticized" (Henry et al. 2016: 236).

Similarly, Kibler and Kautonen (2016) analyzed the role of the perceived moral legitimacy of entrepreneurs (close to PRC) using logit regression throughout the stages in the entrepreneurial process. They found a positive effect of moral legitimacy for a joint sample, with the odds of women advancing in the process being 27 to $51 \%$ lower than those of men. Our results serve to interpret their findings. Since only masculine GRO women react positively to perceived culture, it is probably these women (and possibly most men in their sample) who are positively influenced by the moral legitimacy of entrepreneurs.

The coefficients for our study variables compare well with other well-established antecedents of entrepreneurial

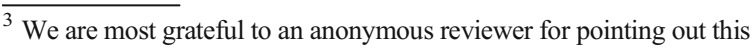
issue to us.
}

behavior. Thus, the significant $\beta$ coefficients for masculine and androgynous GROs are close to that of previous self-employment experience $(\beta=.521, p<.001)$. Besides, they are clearly higher than other traditional antecedents, such as entrepreneurship training $(\beta=.140$, n.s.) or a positive father $\operatorname{RM}(\beta=.225$, n.s. $){ }^{4}$ To measure effect sizes, the use of odds ratios is recommended (Durlak 2009). We can compare the odds ratios in Fig. 2 (comparing the odds of being in stage 2 or beyond against being in stage 1 - have not thought about it) with Kibler and Kautonen's (2016) results. They found the equivalent odds of advancing from "never thought" to "thinking and beyond" to be 1.52 for perceived moral legitimacy. In turn, we found these odds to range (depending on the value of PRC) from 1.05 to 2.52 for masculine GRO and from 2.58 to 0.92 for androgynous GRO. When PRC is at its average, the odds are similarly around 1.6 for androgynous and masculine GROs. Thus, they are similar to those of moral legitimacy in Kibler and Kautonen's (2016) study. Overall, therefore, the effect sizes for GROs and for PRC confirm that they are important variables in explaining entrepreneurial involvement.

\subsection{Implications}

Several implications may be derived from this research. In the first place, clearly different patterns emerge among the women identifying themselves with alternative GROs. This is directly replying to the call by Henry et al. (2016) to investigate the complexity of women's entrepreneurship. Women entrepreneurs do differ, and their decisions to enter entrepreneurship are probably the result of several personal, professional, family, and social circumstances. Among these elements, their GRO is an important antecedent of entrepreneurial involvement. Based on our results, women should not be treated as a homogenous whole in entrepreneurship research (Ahl 2006; Henry et al. 2016; Marlow and McAdam 2013). Instead, their GRO needs be taken into account.

The importance of GRO is exemplified by the influence of perceived culture. This is a relevant variable, and its influence differs by GRO groups. To the extent that

\footnotetext{
${ }^{4}$ As an additional test, we run the same regression for the full combined sample (male and female respondents) including the "sex" variable $(1=$ male; $2=$ female $)$. The coefficient for sex was $\beta=-.282(p<.001)$, lower in absolute value to those of masculine $\operatorname{GRO}(\beta=.337, p<.003)$ and androgynous $\operatorname{GRO}(\beta=.390, p<.001)$. This may clearly be taken as an indication that the effect of GROs is more relevant in explaining entrepreneurial involvement than is sex, in line with previous results by Pérez-Quintana et al. (2017).
} 
Table 4 Differential effect of PRC on entrepreneurial involvement for women with different GRO

\begin{tabular}{|c|c|c|c|c|c|c|c|c|}
\hline \multirow[t]{2}{*}{ Interaction terms } & \multicolumn{2}{|c|}{ Undiffer. GRO } & \multicolumn{2}{|c|}{ Masculine GRO } & \multicolumn{2}{|c|}{ Feminine GRO } & \multicolumn{2}{|c|}{ Androgynous GRO } \\
\hline & $\beta$ & $(\mathrm{SE})$ & $\beta$ & $(\mathrm{SE})$ & $\beta$ & (SE) & $\beta$ & (SE) \\
\hline Undifferentiated GRO & --- & --- & $-0.3552^{* *}$ & $(0.1744)$ & -0.1003 & $(0.1825)$ & 0.0761 & $(0.1601)$ \\
\hline Masculine GRO & $0.3552^{* *}$ & $(0.1744)$ & --- & --- & 0.2549 & $(0.1830)$ & $0.4313^{* * *}$ & $(0.1606)$ \\
\hline Feminine GRO & 0.1003 & $(0.1825)$ & -0.2549 & $(0.1830)$ & --- & --- & 0.1764 & $(0.1692)$ \\
\hline Androgynous GRO & -0.0761 & $(0.1601)$ & $-0.4313^{* * *}$ & $(0.1606)$ & -0.1764 & $(0.1692)$ & --- & --- \\
\hline
\end{tabular}

The coefficient indicates the differential effect of PRC on entrepreneurial involvement for women with the GRO in the row, against women with the GRO in the column (reference group). In the first column (with Undifferentiated GRO women as the reference group), the coefficients are the same as those in Table 3, Model 2. SE Standard errors. Significance levels: *** $p<0.01, * * p<0.05, * p<0.1$

entrepreneurship is connected with a masculine stereotype, as seems to be the case in Spain (Hancock et al. 2014; Laguía et al. 2018), women with different GROs will react differently to what they see as social support to traditional (masculine) entrepreneurship. Thus, it would be sensible to describe and promote entrepreneurship profiles that are not aligned with the traditional masculine stereotype. Among the different options, the most promising one is probably the androgynous entrepreneurial profile (Mueller and Conway Dato-On 2013). According to Hancock et al. (2014), these androgynous entrepreneurial traits would include creativity, optimism, innovativeness, and being active, analytic, and spontaneous. To the extent that entrepreneurship is becoming more strongly identified with these traits, rather than the traditional masculine ones, this would facilitate the entrepreneurial decision in androgynous women.
But of course, culture is stable and changes slowly (Scott 1995; Welter 2011). At a lower scale, the entrepreneurship promotion measures and programs probably need to be tailored to the specific GRO of the participants. If they activate an ideal image of the entrepreneur that is in line with the traits associated with the GRO of the target participants, it will probably have a greater effect on their decisions and actions. In this sense, differentiating programs and measures by their target GRO participants, rather than by their sex, may be more effective. At the very least, using a range of entrepreneurial role models and ideal figures linked not only with masculine, but also androgynous and feminine GRO traits would be reasonable. In this sense, the parallel with the transformational leadership style vs. the traditional one is evident (Harrison et al. 2015).

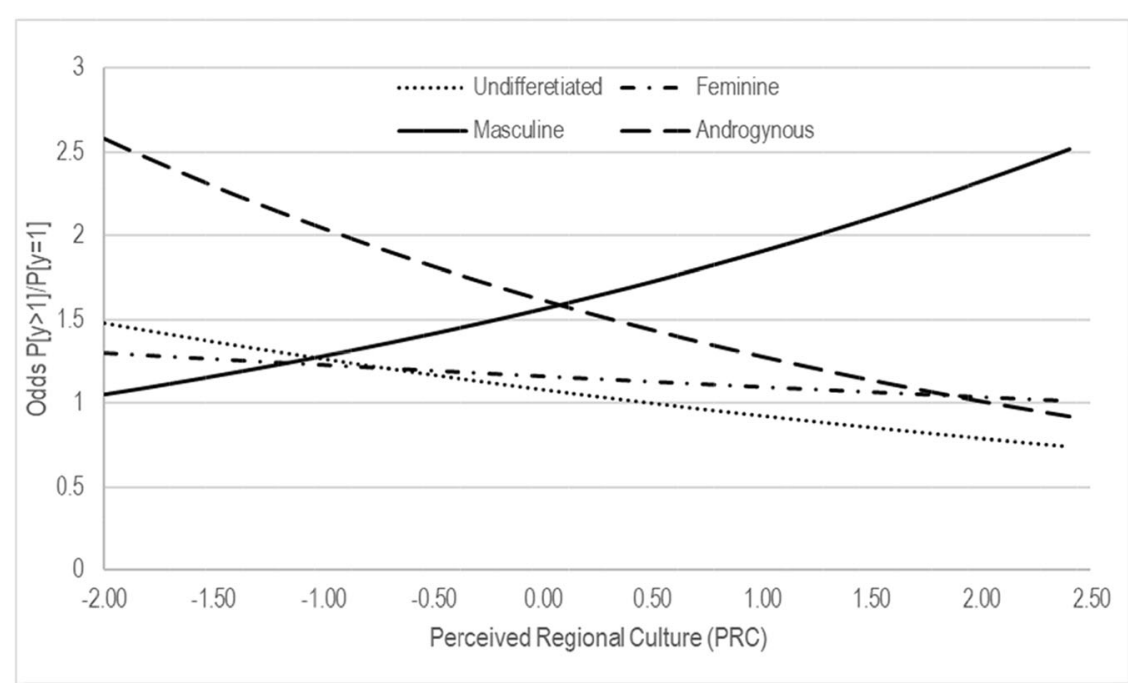

Fig. 2 Ordered Odds of advancing in the entrepreneurial process $(m>1)$ compared to not being involved $(m=1)$ for 4 GRO categories when PRC varies 
Finally, our research has focused exclusively on women. Nevertheless, previous research has confirmed that both men and women identify themselves with one of the four GROs (Gupta et al. 2009, 2013; Mueller and Conway Dato-on 2008, 2013). For this reason, we can expect to find internal differences in the entrepreneurial career of men based on their GRO. It would be most interesting to consider whether the traditional masculine stereotype of the entrepreneur prevalent in Spain is felt as an encouragement or discouragement by different GRO men, or rather men are unaffected by their perceptions of culture.

\subsection{Limitations and future research lines}

This study, as any other, is not without limitations. In the first place, the sample comes from one single country (Spain). Since we are analyzing the influence of perceived culture, the characteristics of the shared national culture may exert an effect. To overcome this limitation, similar studies should be carried out in countries with diverse cultural features. In this way, the potential crosslevel influence could be taken into account. In particular, the majority of the sample comes from one single region (Andalusia), but the control variables included in the analyses should have compensated for this. ${ }^{5}$

Secondly, our sample comes from two different subgroups of the population (entrepreneurship-center users and university alumni). This has been done to guarantee an adequate representativeness and variation in the sample. We have controlled for this with the E-center variable. The fact that it was significant means that there are differences in entrepreneurship involvement between the two groups. However, our results are meaningful after controlling for this variable, which adds robustness to our study. In the future, this research design could be replicated with different samples to test the extent to which they may be generalized, or to assess the influence of other potentially relevant elements.

Thirdly, the data are cross-sectional, preventing us from being able to claim causality. Additionally, as discussed above, we cannot rule out the possibility of reversed causality (that advancement through the entrepreneurial process makes androgynous women have a less favorable perception of their regional culture). A longitudinal design (e.g., tracking these women to follow their changes throughout the entrepreneurial process) would be needed

\footnotetext{
5 Additionally, we separately computed the research model for respondents in Andalusia and for those in the rest of the country, with the results being similar to those reported in this article.
}

to confirm that GRO and PRC are truly causal in explaining entrepreneurship involvement. We plan to do so in the future. Our sample is large, and this should compensate for the usual attrition rates in longitudinal studies. Nevertheless, around half of our women are not engaged at all in entrepreneurship. Most of them will likely remain so in the future and will reduce our usable sample.

\section{Conclusion}

This study is novel in that it assesses the joint influence of gender-role orientation and perceived supportiveness of culture in the advancement through the entrepreneurial career path. Unlike previous research focusing on personal perceptions (Goktan and Gupta 2015; Mueller and Conway Dato-on 2013), we analyze actual involvement in entrepreneurship. The results indicate that women with a masculine orientation are more likely to develop entrepreneurial careers, and especially so when they perceive that the culture around them is pro-entrepreneurial. Androgynous women are also more likely to advance in the process in general. But, in sharp contrast, they are less likely to do so if they perceive that the culture is supportive of entrepreneurship.

The present study, therefore, has shown that the debate about women's entrepreneurship needs to be definitively expanded to fully acknowledge the relevance of genderrole orientations. In this sense, it contributes to the women's entrepreneurship stream of research. Additionally, it provides evidence supporting the validity of the "think entrepreneur, think male" paradigm (de Pillis and Meilich 2006; Laguía et al. 2018). The study has focused only on women and, in so doing, has avoided the criticized bias in comparing men and women (Ahl 2006; Marlow and McAdam 2013). We have centered the analysis on the similarities and differences between alternative groups of women. This, we believe, holds promise of more enlightening results in the future, and therefore, we call for future research to persevere in this approach.

Acknowledgments We are most grateful to the guest editors and the three anonymous reviewers for their most constructive comments and guidance during the whole review process.

Funding This research is part of the ELITE Project (https:// www.researchgate.net/project/ELITE-Emergence-of-high-impact-entrepreneurs) and has benefitted from the funding from the Spanish National R+D Plan (Ministerio de Economía y Competitividad. Ref.: ECO2016-75655-P). 


\section{Appendix}

A1. Exploratory Factor Analysis (EFA) for Bem's Sex-Role Inventory, short-version (12 items)

The data structure is suitable for EFA, according to the Kaiser-Meyer-Olkin measure of sampling adequacy $(0.830)$ and Bartlett's test of sphericity (Approx. Chisquared $=12,385.270, \mathrm{df}=66$, Sig. $=0.000$. Communalities range from a low of 0.369 ("makes decision easily") to a high of 0.742 ("warm"). Two factors have eigenvalues greater than 1 and the cumulative variance explained is $55.7 \%$. After rotation, the sums of squared loadings are 3.789 (component 1) and 3.500 (component 2).

\section{A2. Exploratory Factor Analysis (EFA) for Perceived Regional Culture (PRC)}

The data structure is suitable for EFA, according to the Kaiser-Meyer-Olkin measure of sampling adequacy (0.842) and Bartlett's test of sphericity (Approx. Chisquared $=6670.879, \mathrm{df}=10, \mathrm{Sig} .=0.000$. Communalities range from a low of 0.642 ("the predominant culture in my region... stimulates creativity and innovation") to a high of 0.766 (“...emphasizes self-sufficiency, autonomy and personal initiative"). One factor has an

Table 5 EFA pattern matrix for BSRI

\begin{tabular}{lcr}
\hline & \multicolumn{2}{l}{ Component $^{\mathrm{a}}$} \\
\cline { 2 - 3 } & 1 & 2 \\
\hline A1.Gentle & $\mathbf{. 6 5 6}$ & .105 \\
A1.Sympathetic & $\mathbf{. 6 5 5}$ & .197 \\
A1.Has leadership abilities & .022 & $\mathbf{. 8 4 6}$ \\
A1.Acts like a leader & -.027 & $\mathbf{. 8 3 8}$ \\
A1.Dominant & -.192 & $\mathbf{. 7 6 3}$ \\
A1.Tender & $\mathbf{. 8 2 9}$ & -.167 \\
A1.Warm & $\mathbf{. 8 7 9}$ & -.071 \\
A1.Affectionate & $\mathbf{. 8 6 4}$ & -.069 \\
A1.Strong personality & .064 & $\mathbf{. 6 2 1}$ \\
A1.Defends own's beliefs & .205 & $\mathbf{. 5 6 4}$ \\
A1.Sensitive to others' needs & $\mathbf{. 5 6 8}$ & .174 \\
A1.Makes decisions easily & .064 & $\mathbf{. 5 8 6}$ \\
\hline
\end{tabular}

Note: The indicators loading more heavily in each component are marked in boldface

Extraction method: principal component analysis. Rotation method: oblimin with Kaiser normalization

${ }^{\text {a }}$ Rotation converged in 6 iterations
Table 6 EFA component matrix for PRC

\begin{tabular}{ll}
\hline The predominant culture in my region & $\begin{array}{l}\text { Component } \\
\text { a } \\
\end{array}$ \\
\hline $\begin{array}{l}\text { D6. ... supports/values individual success obtained } \\
\text { through personal effort }\end{array}$ & .830 \\
D6. ... emphasizes self-sufficiency, autonomy and & .875 \\
personal initiative & .827 \\
D6. ... stimulates the assumption of business risk & .801 \\
D6. ... stimulates creativity and innovation & .833 \\
D6.... emphasizes that the individual is responsible for & \\
managing their life &
\end{tabular}

Extraction method: principal component analysis

a 1 components extracted

eigenvalue greater than 1 and the cumulative variance explained is $69.5 \%$. The extraction sum of squared loadings is 3.473 for the single component.

\section{A3. Regression equations for each GRO category}

Since the four GRO categories are mutually exclusive, the respondents are necessarily in one-and only one- of them. Therefore, we can compute the effect of PRC on entrepreneurial involvement for each GRO category through the following equation:

$$
\begin{aligned}
& \log \Omega(m)_{>m \mid \leq m}=\overline{\text { Control }}+\alpha_{k}+b_{k} \cdot P R C-\tau_{m}, \quad k \\
& =U N D I F, \text { MASC, FEMIN , ANDROG }
\end{aligned}
$$

When all control variables are taken at their average, Eqs. 1 to 4 represent the relationship between PRC and entrepreneurial involvement for each GRO category:

$$
\begin{aligned}
& \text { Undifferentiated }: \log \Omega(m)_{>m \mid \leq m} \\
& \quad=\overline{\text { Control }}+0.000-0.157 \cdot P R C-\tau_{m}
\end{aligned}
$$

Masculine $: \log \Omega(m)_{>m \mid \leq m}$

$$
=\overline{\text { Control }}+0.372+0.198 \cdot P R C-\tau_{m}
$$

Feminine $: \log \Omega(m)_{>m \mid \leq m}$

$$
=\overline{\text { Control }}+0.071-0.057 \cdot P R C-\tau_{m}
$$

Androgynous : $\log \Omega(m)_{>m \mid \leq m}$

$$
=\overline{\text { Control }}+0.404-0.233 \cdot P R C-\tau_{m}
$$

Where $\overline{\text { Control }}$ is the sum of each control variable taken as its average multiplied by its corresponding $\beta$ 
Table 7 PRC effect on the ordered log-odds (logits) for each GRO taking all others as the reference

\begin{tabular}{|c|c|c|c|c|c|c|}
\hline \multirow[t]{2}{*}{ Gender-role orientation } & \multicolumn{3}{|l|}{$\alpha_{k}$} & \multicolumn{3}{|l|}{$b_{k}$} \\
\hline & Coeff. & $\mathrm{SE}$ & $p$ value & Coeff. & SE & $p$ value \\
\hline Undifferentiated & 0 & & & -0.1573 & $(0.1240)$ & 0.205 \\
\hline Masculine & $0.3720 * *$ & $(0.1732)$ & 0.032 & 0.1979 & $(0.1246)$ & 0.112 \\
\hline Feminine & 0.0715 & $(0.1701)$ & 0.674 & -0.0570 & $(0.1350)$ & 0.673 \\
\hline Androgynous & $0.4037 * *$ & $(0.1618)$ & 0.013 & $-0.2334 * *$ & $(0.1020)$ & 0.022 \\
\hline
\end{tabular}

$S E$ standard errors. Significance levels: $* * * p<0.01, * * p<0.05, * p<0.1$

coefficient. The independent term $\left(a_{k}\right)$ is the direct effect of each particular GRO, taken directly from the OLM regression results in Model 2 (it is 0 for undifferentiated GRO women, since this is taken as the reference category). The PRC coefficient $\left(b_{k}\right)$ is the effect of perceived regional culture for each GRO (it is the sum, for each category, of the PRC coefficient $\beta_{\mathrm{PRC}}$ and the interaction $\beta_{\text {GRO-PRC }}$, both taken from Model 2). The standard deviations and significance levels for the coefficients in Eqs. 1-4 are presented in Table 7.

Open Access This article is licensed under a Creative Commons Attribution 4.0 International License, which permits use, sharing, adaptation, distribution and reproduction in any medium or format, as long as you give appropriate credit to the original author(s) and the source, provide a link to the Creative Commons licence, and indicate if changes were made. The images or other third party material in this article are included in the article's Creative Commons licence, unless indicated otherwise in a credit line to the material. If material is not included in the article's Creative Commons licence and your intended use is not permitted by statutory regulation or exceeds the permitted use, you will need to obtain permission directly from the copyright holder. To view a copy of this licence, visit http://creativecommons.org/licenses/by/4.0/.

\section{References}

Ahl, H. (2006). Why research on women entrepreneurs needs new directions. Entrepreneurship Theory and Practice, 30(5), 595-621.

Ahmed, T., Vafaei, A., Belanger, E., Phillips, S. P., \& Zunzunegui, M. V. (2016). Bem sex role inventory validation in the international mobility in aging study. Canadian Journal on Aging/La revue canadienne du vieillissement, 35(3), 348-360.

Allen, E., Langowitz, N., \& Minniti, M. (2007). The 2006 global entrepreneurship monitor special topic report: Omen in entrepreneurship. Babson Park: Center for Women Leadership, Babson College.

Álvarez, C., Urbano, D., \& Amorós, J. E. (2014). GEM research: achievements and challenges. Small Business Economics, $42(3), 445-465$.
Autio, E., Pathak, S., \& Wennberg, K. (2013). Consequences of cultural practices for entrepreneurial behaviors. Journal of International Business Studies, 44(4), 334-362.

Bandura, A. (1986). Social foundations of thought and action. Englewood Cliffs: Prentice Hall.

Baughn, C. C., Chua, B. L., \& Neupert, K. E. (2006). The normative context for women's participation in entrepreneruship: a multicountry study. Entrepreneurship Theory and Practice, 30(5), 687-708.

Bem, S. L. (1974). The measurement of psychological androgyny. Journal of Consulting and Clinical Psychology, 42(2), 155162.

Bem, S. L. (1981). Bem sex-role inventory: Professional manual. Palo Alto: Consulting Psychologists Press.

Bigelow, L., Lundmark, L., McLean Parks, J., \& Wuebker, R. (2014). Skirting the issues: experimental evidence of gender bias in IPO prospectus evaluations. Journal of Management, 40(6), 1732-1759.

Bönte, W., \& Piegeler, M. (2013). Gender gap in latent and nascent entrepreneurship: driven by competitiveness. Small Business Economics, 41(4), 961-987.

Bosma, N., \& Schutjens, V. (2011). Understanding regional variation in entrepreneurial activity and entrepreneurial attitude in Europe. The Annals of Regional Science, 47(3), 711-742.

Bourdieu, P. (1991). Language and symbolic power. Cambridge: Polity Press.

Breznitz, S. M., \& Zhang, Q. (2019). Determinants of graduates' entrepreneurial activity. Small Business Economics, 1-18. https://doi.org/10.1007/s11187-019-00171-8.

Broverman, I. K., Vogel, S. R., Broverman, D. M., Clarkson, F. E., \& Rosenkrantz, P. S. (1972). Sex-role stereotypes: a current appraisal. Journal of Social Issues, 28(2), 59-78.

Brush, C. G., Carter, N. M., Greene, P. G., Hart, M. M., \& Gatewood, E. (2002). The role of social capital and gender in linking financial suppliers and entrepreneurial firms: a framework for future research. Venture Capital: An International Journal of Entrepreneurial Finance, 4(4), 305-323.

Brush, C. G., Greene, P., Balachandra, L., \& Davis, A. (2018). The gender gap in venture capital- progress, problems, and perspectives. Venture Capital, 20(2), 115-136.

Bullough, A., Renko, M., \& Abdelzaher, D. (2017). Women's business ownership: operating within the context of institutional and in-group collectivism. Journal of Management, 43(7), 2037-2064.

Caliendo, M., Fossen, F. M., \& Kritikos, A. S. (2009). Risk attitudes of nascent entrepreneurs-new evidence from an 
experimentally validated survey. Small Business Economics, $32(2), 153-167$.

Caliendo, M., Fossen, F. M., Kritikos, A., \& Wetter, M. (2015). The gender gap in entrepreneurship: not just a matter of personality. CESifo Economic Studies, 61(1), 202-238.

Camelo-Ordaz, C., Diánez-González, J. P., \& Ruiz-Navarro, J. (2016). The influence of gender on entrepreneurial intention: the mediating role of perceptual factors. $B R Q$ Business Research Quarterly, 19(4), 261-277.

Carver, L. F., Vafaei, A., Guerra, R., Freire, A., \& Phillips, S. P. (2013). Gender differences: Examination of the 12-item Bem Sex Role Inventory (BSRI-12) in an older Brazilian population. PloS one, 8(10), e76356.

Constantinople, A. (1973). Masculinity-femininity: an exception to the famous dictum? Psychological Bulletin, 80, 389-407.

Davidsson, P., \& Wiklund, J. (1997). Values, beliefs and regional variations in new firm formation rates. Journal of Economic Psychology, 18(2-3), 179-199.

de Pillis, E., \& Meilich, O. (2006). Think entrepreneur, think male? Business students' assumptions about a hypothetical entrepreneur. International Journal of Entrepreneurship Education, 4, 3-18.

Deutskens, E., De Ruyter, K., Wetzels, M., \& Oosterveld, P. (2004). Response rate and response quality of internetbased surveys: an experimental study. Marketing Letters, 15(1), 21-36.

Díaz-García, M. C., \& Welter, F. (2013). Gender identities and practices: interpreting women entrepreneurs' narratives. International Small Business Journal, 31(4), 384- 404.

Dodd, S. D., \& Anderson, A. R. (2007). Mumpsimus and the mything of the individualistic entrepreneur. International Small Business Journal, 25(4), 341-360.

Down, S., \& Reveley, J. (2004). Generational encounters and the social formation of entrepreneurial identity: 'young guns' and 'old farts'. Organization, 11(2), 233-250.

Durlak, J. A. (2009). How to select, calculate, and interpret effect sizes. Journal of Pediatric Psychology, 34(9), 917-928.

Eagly, A. H. (1987). Reporting sex differences. American Psychologist, 42(7), 756-757.

Eagly, A. H., \& Carli, L. L. (2003). The female leadership advantage: an evaluation of the evidence. The Leadership Quarterly, 14(6), 807-834.

Etzioni, A. (1987). Entrepreneurship, adaptation and legitimation: a macro-behavioral perspective. Journal of Economic Behavior \& Organization, 8(2), 175-189.

Frese, T., Geiger, I., \& Dost, F. (2019). An empirical investigation of determinants of effectual and causal decision logics in online and high-tech start-up firms. Small Business Economics, 1-24. https://doi.org/10.1007/s11187-01900147-8

García-Cabrera, A. M., \& García-Soto, M. G. (2008). Cultural differences and entrepreneurial behaviour: an intra-country cross-cultural analysis in Cape Verde. Entrepreneurship \& Regional Development, 20(5), 451-483.

Goktan, A. B., \& Gupta, V. K. (2015). Sex, gender, and individual entrepreneurial orientation: evidence from four countries. International Entrepreneurship and Management Journal, 11(1), 95-112.
Gupta, V. K., Turban, D. B., \& Bhawe, N. M. (2008). The effect of gender stereotype activation on entrepreneurial intentions. Journal of Applied Psychology, 93(5), 1053-1061.

Gupta, V. K., Turban, D. B., Wasti, S. A., \& Sikdar, A. (2009). The role of gender stereotypes in perceptions of entrepreneurs and intentions to become an entrepreneur. Entrepreneurship Theory and Practice, 33(2), 397-417.

Gupta, V. K., Turban, D. B., \& Pareek, A. (2013). Differences between men and women in opportunity evaluation as a function of gender stereotypes and stereotype activation. Entrepreneurship Theory and Practice, 37(4), 771-788.

Gupta, V. K., Wieland, A. M., \& Turban, D. B. (2019). Gender characterizations in entrepreneurship: a multi-level investigation of sex-role stereotypes about high-growth, commercial, and social entrepreneurs. Journal of Small Business Management, 57(1), 131-153.

Hancock, C., Pérez-Quintana, A., \& Hormiga, E. (2014). Stereotypical notions of the entrepreneur: an analysis from a perspective of gender. Journal of Promotion Management, 20(1), 82-94.

Harrison, R., Leitch, C., \& McAdam, M. (2015). Breaking glass: toward a gendered analysis of entrepreneurial leadership. Journal of Small Business Management, 53(3), 693-713.

Hayton, J. C., \& Cacciotti, G. (2013). Is there an entrepreneurial culture? A review of empirical research. Entrepreneurship \& Regional Development, 25(9-10), 708-731.

Hayton, J. C., George, G., \& Zahra, S. A. (2002). National culture and entrepreneurship: a review of behavioral research. Entrepreneurship Theory and Practice, 26(4), 33-52.

Hechavarría, D. M., Terjesen, S. A., Ingram, A. E., Renko, M., Justo, R., \& Elam, A. (2017). Taking care of business: the impact of culture and gender on entrepreneurs' blended value creation goals. Small Business Economics, 48(1), 225-257.

Henry, C., Foss, L., \& Ahl, H. (2016). Gender and entrepreneurship research: a review of methodological approaches. International Small Business Journal, 34(3), 217-241.

Hernández-Sánchez, B. R., Sánchez-García, J. C., \& Mayens, A. W. (2019). Impact of entrepreneurial education programs on total entrepreneurial activity: the case of Spain. Administrative Sciences, 9(1), 25.

Hindle, K., Klyver, K., \& Jennings, D. F. (2009). An "informed" intent model: Incorporating human capital, social capital, and gender variables into the theoretical model of entrepreneurial intentions. In A. Carsrud \& M. Brännback (Eds.), Understanding the entrepreneurial mind: Opening the black box (pp. 35-50). New York: Springer.

Hirschi, A., \& Fischer, S. (2013). Work values as predictors of entrepreneurial career intentions: a longitudinal analysis of gender effects. Career Development International, 18(3), 216-231.

Hofstede, G. (1998). The cultural construction of gender. In G. Hofstede (Ed.), Masculinity and femininity: The taboo dimension of national cultures. Thousand Oaks: Sage Publications Inc.

Hofstede, G. (2003). Culture's consequences: Comparing values, behaviors, institutions and organizations across nations (2nd ed.). Newbury Park: Sage Publications.

Hughes, K. D., Jennings, J. E., Brush, C. G., Carter, S., \& Welter, F. (2012). Extending women's entrepreneurship research in new directions. Entrepreneurship Theory and Practice, $36(3), 429-442$. 
Jaén, I., \& Liñán, F. (2013). Work values in a changing economic environment: the role of entrepreneurial capital. International Journal of Manpower, 34(8), 939-960.

Jennings, J. E., \& Brush, C. G. (2013). Research on women entrepreneurs: challenges to (and from) the broader entrepreneurship literature? Academy of Management Annals, 7(1), 663-715.

Kautonen, T., van Gelderen, M., \& Fink, M. (2015). Robustness of the theory of planned behavior in predicting entrepreneurial intentions and actions. Entrepreneurship Theory and Practice, 39(3), 655-674.

Kibler, E., \& Kautonen, T. (2016). The moral legitimacy of entrepreneurs: an analysis of early-stage entrepreneurship across 26 countries. International Small Business Journal, 34(1), 34-50.

Kibler, E., Kautonen, T., \& Fink, M. (2014). Regional social legitimacy of entrepreneurship: implications for entrepreneurial intention and start-up behaviour. Regional Studies, 48(6), 995-1015.

Koenig, A. M., Eagly, A. H., Mitchell, A. A., \& Ristikari, T. (2011). Are leader stereotypes masculine? A meta-analysis of three research paradigms. Psychological Bulletin, 137(4), 616.

Krueger, N. F., Liñán, F., \& Nabi, G. (2013). Cultural values and entrepreneurship. Entrepreneurship and Regional Development, 25(9-10), 703-707.

Laguía, A., García-Ael, C., Wach, D., \& Moriano, J. A. (2018). "Think entrepreneur-think male": A task and relationship scale to measure gender stereotypes in entrepreneurship. International Entrepreneurship and Management Journal, (online first).

Leitch, C., Welter, F., \& Henry, C. (2018). Women entrepreneurs' financing revisited: taking stock and looking forward. Venture Capital, 20(2), 103-114.

Lenney, E. (1991). Sex role. The measurement of masculinity, femininity and androgyny. In L. S. Robinson \& Wrightsman (Eds.), Measures of personality and social psychological attitudes (Vol. 1, pp. 573-660). San Diego: Academic Press.

Leung, K., \& Morris, M. W. (2015). Values, schemas, and norms in the culture-behavior nexus: a situated dynamics framework. Journal of International Business Studies, 46(9), 1028-1050.

Liñán, F., \& Fernandez-Serrano, J. (2014). National culture, entrepreneurship and economic development: different patterns across the European Union. Small Business Economics, $42(4), 685-701$.

Liñán, F., Urbano, D., \& Guerrero, M. (2011). Regional variations in entrepreneurial cognitions: start-up intentions of university students in Spain. Entrepreneurship and Regional Development, 23(3-4), 187-215.

Liñán, F., Moriano, J. A., \& Jaén, I. (2016). Individualism and entrepreneurship: does the pattern depend on the social context? International Small Business Journal, 34(6), 760-776.

Lounsbury, M., \& Glynn, M. A. (2001). Cultural entrepreneurship: stories, legitimacy, and the acquisition of resources. Strategic Management Journal, 22(6-7), 545-564.

Markus, H. R., \& Kitayama, S. (1991). Culture and the self: implications for cognition, emotion and motivation. Psychological Review, 98, 224-253.

Marlow, S., \& McAdam, M. (2013). Gender and entrepreneurship: advancing debate and challenging myths; exploring the mystery of the under-performing female entrepreneur. International Journal of Entrepreneurial Behavior \& Research, 19(1), 114-124.

Marlow, S., \& Swail, J. (2014). Gender, risk and finance: why can't a woman be more like a man? Entrepreneurship \& Regional Development, 26(1-2), 80-96.

Martin, B. C., McNally, J. J., \& Kay, M. J. (2013). Examining the formation of human capital in entrepreneurship: a metaanalysis of entrepreneurship education outcomes. Journal of Business Venturing, 28(2), 211-224.

Mateo, M., \& Fernández, J. (1991). La dimensionalidad de los conceptos de masculinidad y feminidad. Investigaciones Psicológicas, 9, 95-116.

McCoy, S., Galletta, D. F., \& King, W. R. (2005). Integrating national culture into IS research: the need for current individual level measures. Communications of the Association for Information Systems, 15, 211-224.

McGrath, R. G., \& MacMillan, I. C. (1992). More like each other than anyone else - a cross-cultural study of entrepreneurial perceptions. Journal of Business Venturing, 7(5), 419-429.

Mueller, S. L., \& Conway Dato-On, M. (2008). Gender-role orientation as a determinant of entrepreneurial self-efficacy. Journal of Developmental Entrepreneurship, 13(1), 3-20.

Mueller, S. L., \& Conway Dato-On, M. (2013). A cross cultural study of gender-role orientation and entrepreneurial self-efficacy. International Entrepreneurship and Management Journal, 9(1), 1-20.

Mueller, S. L., \& Thomas, A. S. (2001). Culture and entrepreneurial potential: a nine country study of locus of control and innovativeness. Journal of Business Venturing, 16(1), 51-75.

Nabi, G., Liñán, F., Fayolle, A., Krueger, N., \& Walmsley, A. (2017). The impact of entrepreneurship education in higher education: a systematic review and research agenda. Academy of Management Learning \& Education, 16(2), 277-299.

Nabi, G., Walmsley, A., Liñán, F., Akhtar, I., \& Neame, C. (2018). Does entrepreneurship education in the first year of higher education develop entrepreneurial intentions? The role of learning and inspiration. Studies in Higher Education, 43(3), 452-467.

Neumeyer, X., Santos, S. C., Caetano, A., \& Kalbfleisch, P. (2019). Entrepreneurship ecosystems and women entrepreneurs: a social capital and network approach. Small Business Economics, 53(2), 475-489.

Noguera, M., Alvarez, C., Merigo, J. M., \& Urbano, D. (2015). Determinants of female entrepreneurship in Spain: an institutional approach. Computational and Mathematical Organization Theory, 21(4), 341-355.

Peña, I., Guerrero, M., González-Pernía, J. L., \& Montero, J. (2019). Global entrepreneurship monitor: Informe GEM España 2018-2019. Santander: Ed. Universidad de Cantabria \& Asociación Red GEM España.

Perez-Quintana, A., Hormiga, E., Martori, J. C., \& Madariaga, R. (2017). The influence of sex and gender-role orientation in the decision to become an entrepreneur. International Journal of Gender and Entrepreneurship, 9(1), 8-30.

Reynolds, P. D., Bosma, N., Autio, E., Hunt, S., De Bono, N., Servais, I., et al. (2005). Global entrepreneurship monitor: data collection design and implementation 1998-2003. Small Business Economics, 24(3), 205-231. 
Reynolds, P. D., Autio, E., \& Hechavarria, D. M. (2008). Global entrepreneurship monitor (GEM): Expert questionnaire data. Ann Arbor: Inter-university Consortium for Political and Social Research.

Santos, F. J., Roomi, M. A., \& Liñán, F. (2016). About gender differences and the social environment in the development of entrepreneurial intentions. Journal of Small Business Management, 54(1), 49-66.

Schein, V. E. (2001). A global look at psychological barriers to women's progress in management. Journal of Social Issues, 57, 675-688.

Scherer, R. F., Brodzinsky, J. D., \& Wiebe, F. A. (1991). Examining the relationship between personality and entrepreneurial career preference. Entrepreneurship and Regional Development, 3, 195-206.

Schwartz, S. H. (1999). A theory of cultural values and some implications for work. Applied Psychology: An International Review, 48(1), 23-47.

Scott, W. R. (1995). Institutions and organizations. Thousand Oaks: Sage Publications Inc..

Scott, W. R. (2010). Reflections: The past and future of research on institutions and institutional change. Journal of Change Management, 10(1), 5-21.

Shane, S. A. (2003). A general theory of entrepreneurship: The individual-opportunity nexus. New horizons in entrepreneurship series. Cheltenham: E. Elgar.

Shifren, K., \& Bauserman, R. (1996). The relationship between instrumental and expressive traits, health behaviors, and perceived physical health. Sex Roles, 34(11-12), 841-864.

Shinnar, R. S., Giacomin, O., \& Janssen, F. (2012). Entrepreneurial perceptions and intentions: the role of gender and culture. Entrepreneurship: Theory and Practice, 36(3), 465-493.

Shinnar, R. S., Hsu, D. K., Powell, B. C., \& Zhou, H. (2018). Entrepreneurial intentions and start-ups: are women or men more likely to enact their intentions? International Small Business Journal, 36(1), 60-80.

Shneor, R., Metin Camgöz, S., \& Bayhan Karapinar, P. (2013). The interaction between culture and sex in the formation of entrepreneurial intentions. Entrepreneurship \& Regional Development, 25(9-10), 781-803.

Siu, W.-S. S., \& Lo, E. S.-C. (2013). Cultural contingency in the cognitive model of entrepreneurial intention. Entrepreneurship: Theory and Practice, 37(2), 147-173.
Spence, J. T., \& Buckner, C. E. (2000). Instrumental and expressive traits, trait stereotypes, and sexist attitudes: what do they signify? Psychology of Women Quarterly, 24(1), 44-62.

Stenholm, P., Acs, Z. J., \& Wuebker, R. (2013). Exploring country-level institutional arrangements on the rate and type of entrepreneurial activity. Journal of Business Venturing, 28(1), 176-193.

Stephan, U., \& Uhlaner, L. M. (2010). Performance-based vs socially supportive culture: a cross-national study of descriptive norms and entrepreneurship. Journal of International Business Studies, 41(8), 1347-1364.

Steyaert, C. (2007). "Entrepreneuring” as a conceptual attractor? A review of process theories in 20 years of entrepreneurship studies. Entrepreneurship \& Regional Development, 19(6), 453-477.

Suchman, M. C. (1995). Managing legitimacy: strategic and institutional approaches. Academy of Management Review, 20(3), 571-610.

Thornton, P. H., Ribeiro-Soriano, D., \& Urbano, D. (2011). Sociocultural factors and entrepreneurial activity. International Small Business Journal, 29(2), 105-118.

Verheul, I., Thurik, R., Grilo, I., \& Van der Zwan, P. (2012). Explaining preferences and actual involvement in self-employment: gender and the entrepreneurial personality. Journal of Economic Psychology, 33(2), 325-341.

Welter, F. (2011). Contextualizing entrepreneurship - conceptual challenges and ways forward. Entrepreneurship Theory and Practice, 35(1), 165-184.

Welter, F., \& Smallbone, D. (2011). Institutional perspectives on entrepreneurial behavior in challenging environments. Journal of Small Business Management, 49(1), 107-125.

Whetten, D. A. (2009). An examination of the interface between context and theory applied to the study of Chinese organizations. Management and Organization Review, 5(1), 2956.

Wood, W., \& Eagly, A. H. (2002). A cross-cultural analysis of the behavior of women and men: implications for the origins of sex differences. Psychological Bulletin, 128(5), 699-727.

Publisher's note Springer Nature remains neutral with regard to jurisdictional claims in published maps and institutional affiliations. 